\title{
AN EXPERIMENT ON SIMULTANEOUS OPERATION OF NITRIFICATION AND DENITRIFICATION OF MUNICIPAL LANDFILL LEACHATE IN A SINGLE REACTION TANK
}

\author{
KOHJI MICHIOKU ${ }^{1}$, KENJI TANAKA ${ }^{2}$, HIROYA TANAKA ${ }^{2}$, KOSUKE INOUE $^{2}$, \\ TAMIHIRO NAKAMICHI ${ }^{3}$, MASAHIRO YAGI $^{3} \&$ NARIAKI WADA $^{4}$ \\ ${ }^{1}$ Department of Civil and Environmental Engineering, Hosei University, Japan \\ ${ }^{2}$ Former Graduate Student, Kobe University, Japan \\ ${ }^{3}$ Kobe Institute of Health, Kobe City, Japan \\ ${ }^{4}$ Faculty of Environmental Science, University of Shiga Prefecture, Japan
}

\begin{abstract}
Leachate from municipal disposal landfill brings a significant load of ammonia in receiving waters. Since phosphorus and degradable organic carbon are mostly filtered out from the leachate in the course of subsurface runoff, conventional treatment technology such as activated sludge process is not available for nitrogen removal from the leachate. The authors are developing a new biological technology of low-cost leachate treatment which consists of nitrification with micro-bubble (MB) aeration and denitrification by using fatty acid compounds, FAC. Laboratory experiments showed that denitrification was in progress even in an aerobic reactor, when carriers coated with FAC were equipped in the aeration tank. The result indicates that both the nitrification and denitrification simultaneously occurred in a single reaction tank, which suggests there is the possibility to devise an economically feasible treatment system with a very simple structure. The biochemical nitrogen removal mechanism involved in the proposed system is considered to be like the following. First, the anoxic leachate was nitrified by the MB aeration and most of ammonia was oxidized into nitrate. Secondly, the nitrate was reduced and denitrified in an anoxic sub-layer of denitrifying bacteria biofilms that were formed on the surface of carriers. In the denitrification process, FAC contributes to denitrification in two ways. The first is to consume dissolved oxygen and to create anaerobic environment. The second is to nourish denitrifying bacteria as a hydrogen donor and carbon source. Such biochemical processes were experimentally investigated by analysing water quality balance. This study provides an insight into scientific background for labour and energy saving technology of leachate treatment.

Keywords: nitrification, denitrification, leachate, dissolved oxygen, hydrogen feeding agent.
\end{abstract}

\section{INTRODUCTION}

Prior to the enactment of the waste management and public cleansing law in 1970, a huge amount of municipal solid waste was directly dumped in more than 1,500 landfills in Japan with no treatment. Since about $70 \%$ of them are located in mountain areas, significant pollutant loads were released from the landfills to receiving streams especially after heavy rainfalls. In many cases, leachate treatment is required in order to minimize the pollutant load to the receiving waters. Leachate from waste-dumped landfills has generally very different water quality from ordinary groundwater runoff as well as from municipal sewage waters. Most of the organic matters and phosphorous substances contained in the solid wastes are filtered out and oxygen is completely consumed in the course of retention, infiltration and through travelling underground.

The field site in this study is a municipal waste landfill located in a mountain area in Kobe City, where huge amounts of municipal solid waste was dumped with the rapid growth of socioeconomic activities in the 1960s to 1970s. Ammonia nitrogen $\mathrm{NH}_{4}-\mathrm{N}$ and dissolved hardly decomposable organic matters are the dominant contaminant substances in the anoxic leachate. During the first ten years after starting the treatment, the nitrogen concentration of the leachate was frequently recorded at larger than $500 \mathrm{~T}-\mathrm{Nmg} / \mathrm{l}$. Then, it has gradually 
decreased to $30 \sim 100 \mathrm{~T}-\mathrm{Nmg} / \mathrm{l}$ but it is still irregularly fluctuating and sometimes exceeds the target level of $60 \mathrm{~T}-\mathrm{Nmg} / \mathrm{l}$. Therefore, some countermeasures against the extra pollutant loading are needed to avoid the environmental hazard in downstream areas.

Biological treatment of nitrogen generally consists of two stages; nitrification and denitrification processes [1]. Nitrification is the process in which ammonium or ammonia is oxidized into nitrite by ammonia-oxidizing bacteria (AOB). The nitrite is further oxidized into nitrate by nitrite-oxidizing bacteria (NOB). Denitrification is the process which reduces nitrates to nitrogen gas with the aid of denitrifying bacteria (DB). Performance of nitrogen removal from landfill leachate was investigated by using a sequencing batch reactor (SBR) after ozone oxidization [2]. A system which combined an anaerobic sequencing batch reactor (ASBR) with the pulse sequencing batch reactor (PSBR) was proposed by Zhu et al. [3]. Many other technologies were proposed for removing nitrogen, such as a rotating biological contactor (RBC) [4], membrane biological reactors [5], ion exchange resins technique [6], constructed wetlands [7] and so on. Jokela et al. [8] are among those who focused their attention on a labour and energy saving treatment system.

In our field site of landfill, the leachate has been treated in a plant more than 40 years after finishing the landfill by using a biological nitrification/denitrification process similar to sewage water treatment plants. Such a concentrated treatment facility is economically feasible in the case of a young landfill site, but it is no longer the case with aged landfills similar to the present case. The plant is now aging and needs to be replaced as soon as possible by an alternative facility that is more economically and environmentally sustainable.

The authors have developed a new technology of leachate treatment consisting of twostep processes of nitrogen removal. The first step is conversion of ammonia to nitrate by using "Micro-Bubble" (MB) aeration. The second step is denitrification, which is achieved with the aid of fatty acid compounds (FAC) as hydrogen donor [9], [10]. In the last few years, laboratory and field experiments on the MB aeration system have been carried out to examine its nitrification performance of leachate [11], [12]. Denitrification of leachate was experimentally investigated in a test column filled with FAC and an excellent performance of FAC was confirmed in denitrification, where the FAC functions as hydrogen donor and carbon source to nourish heterotrophic bacteria [13].

In this study, a preliminary experiment on simultaneous operation of nitrification and denitrification was carried out by integrating the two steps of treatment, where carriers coated with FAC are equipped in a MB aeration tank. Treatment performance of the proposed system was investigated by analysing balances of dissolved oxygen, organic matters and nitrogen components.

\section{EXPERIMENTAL SETUP}

\subsection{Equipment}

A laboratory experiment was carried out in a rectangular FRP test tank with a volume capacity of $1.0 \mathrm{~m}^{3}$. A MB aerator was equipped in order to oxidize ammonia to nitrate. In addition, carriers coated with FAC were filled in the tank to promote denitrification. As discussed above, the carriers with FAC coating were expected to function not only as hydrogen donor but also as carbon source to nourish heterotrophic bacteria. Well-developed microorganism biofilms are observed on the surface of carriers.

In order to examine the performance of the MB aeration and the FAC carriers individually, three cases of experiments were conducted as illustrated in Fig. 1. The carrier is pictured in Fig. 2, where FAC was coated on plastic carrier elements. 


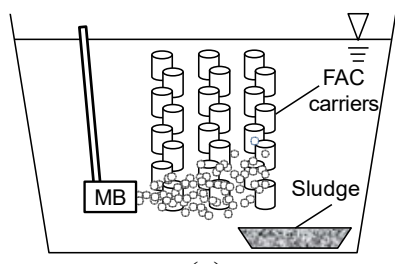

(a)

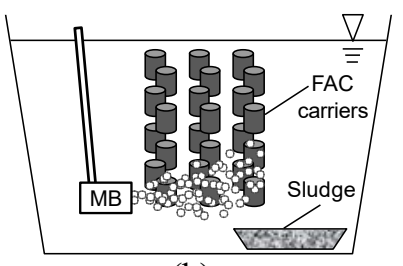

(b)

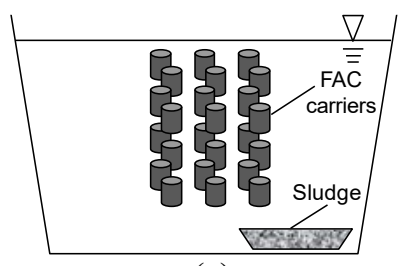

(c)

Figure 1: Experimental setup. (a) Case-1: Carriers with FAC coating and MB aeration; (b) Case-2: Carriers with no FAC coating and MB aeration; (c) Case-3: Carriers with no FAC coating and no aeration.

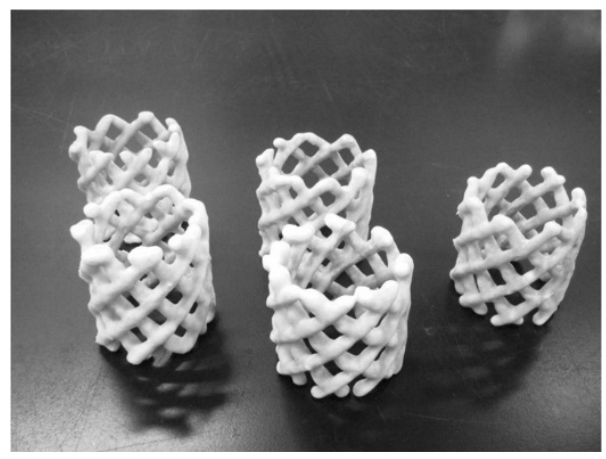

Figure 2: Carriers with FAC coating.

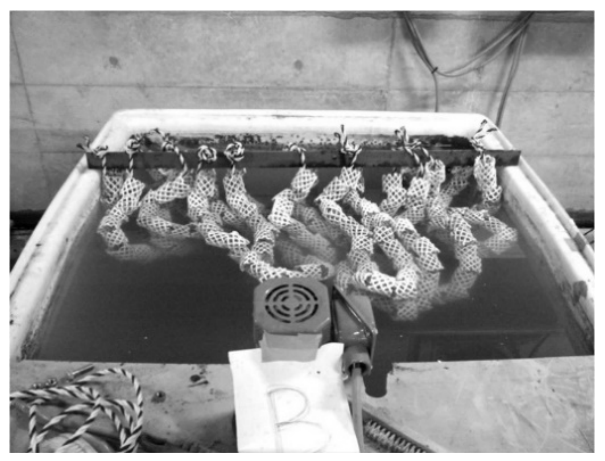

Figure 3: Overview of Case-1.

\subsection{Experimental conditions and procedures}

In Case-1, the FAC carriers were filled and the MB aerator was equipped in the test tank. Fig. 3 shows an overview of Case-1. In Case-1, the leachate was aerated by MB and most of ammonia was immediately oxidized into nitrate. At the same time, the nitrate is biochemically reduced in an anaerobic sublayer of the microorganism biofilm formed on the FAC carrier's surface. It is expected that the FAC promotes to denitrify the leachate in two ways. The first is to consume dissolved oxygen and to keep the microorganism biofilm locally anoxic in spite of the ambient water being aerated by MB. The second is to nourish denitrifying bacteria by feeding hydrogen and carbon.

Case-2 in the experiment was conducted to evaluate the nitrification performance of the MB aeration, individually. In this case, the carriers were not coated by FAC and little denitrification would occur. Denitrification performance of FAC carriers can be investigated by comparing the results between Case- 1 and 2 .

Case- 3 is a reference case or a control, where both FAC and MB aeration were absent. By comparing Case-2 and 3, nitrification performance of the MB aeration can be evaluated.

In every case, a small tray filled with sludge collected from the leachate reservoir was placed in the test tank as a source of nitrifiers and denitrifiers.

Fig. 3 shows an overview of Case-1. The experiment was carried out in a basement of a sprinkling filter tower of the treatment plant so that the leachate can be easily fed to the test tank. The laboratory hall was not air-conditioned and water temperature gradually decreased 
from September to December as shown in Fig. 4. Water was sampled to examine quality once a week in every experimental run. After spending all the ammonia nitrogen by nitrification, water in the tank was totally replaced by fresh leachate and a new experimental run started under another condition of MB aeration discharge.

Three experimental runs were carried out in each case. The carriers were not replaced by new ones when another experimental run started but succeeded to the next run to conserve the microorganism's conditions.

\subsection{Water quality components}

Collecting the water samples once a week, concentration of total organic carbon, TOC, total nitrogen, T-N, ammonia nitrogen, $\mathrm{NH}_{4}-\mathrm{N}$, nitrite nitrogen, $\mathrm{NO}_{2}-\mathrm{N}$, nitrate nitrogen, $\mathrm{NO}_{3}-\mathrm{N}$, and phosphoric acid, $\mathrm{PO}_{4}-\mathrm{P}$, were analysed. Dissolved oxygen, $\mathrm{DO}$, water temperature and hydrogen ion concentration $\mathrm{pH}$ were also measured. The first experimental run, Run-1, was carried out with a 24-hour operation per day of MB aeration. After about three weeks, $\mathrm{NH}_{4}$ $\mathrm{N}$ was consumed out by nitrification in Case-1. Then, water in all the test tanks was replaced by fresh leachate and the second experimental run, Run-2, started with a half aeration discharge of Run-1, i.e. aeration discharge in sequence of 15-minute operation and 15-minute stop. After another three weeks, biochemical reaction in Run-2 was completed and the water was replaced by fresh leachate again. The last experimental run, Run-3, started with one eighth aeration discharge of Run-1, i.e. aeration discharge in sequence of 15 -minute operation and 105-minute stop.

\section{EXPERIMENTAL RESULTS}

Due to insufficient acclimatization before starting the experiment, the biochemical process during Run-1 did not seem to be in an equilibrium state. Therefore, most of our attention should be paid primarily on events occurred during Run-2 and 3. It is additionally noted that microbial activities were somewhat reduced during the latter half period of Run-3 due to low water temperature as shown in Fig. 4.

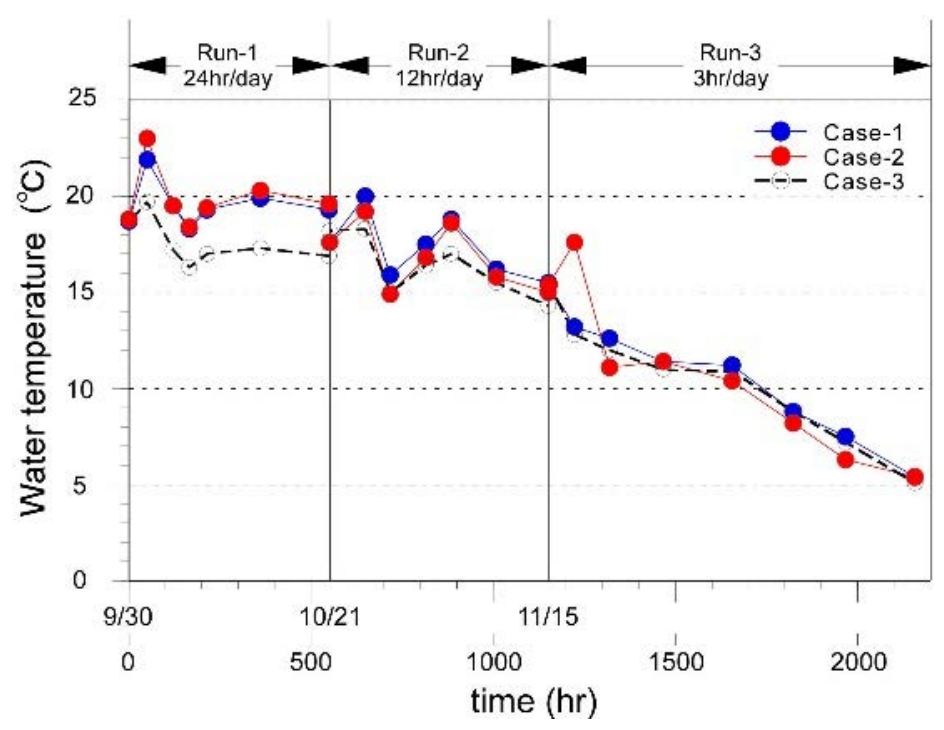

Figure 4: Time histories of water temperature. 


\subsection{Nitrogen: T-N, NH4-N, NO2-N, NO3-N and dissolved oxygen, DO}

Time histories of nitrogen components are plotted in Figs 5-8. As mentioned above, the following discussion will be made primarily focusing on events during Run-2 and 3 in every case.

Fig. 5 shows that T-N concentration in Case-1 immediately dropped soon after starting the runs and then asymptotically decreased to a constant level. The result mentions that a certain quantity of nitrogen was removed by the combined action of MB aerators and FAC carriers. On the other hand, little nitrogen was removed in Case- 2 in which FAC was not coated on the carriers.

It is an interesting feature both in Case- 1 and 2 that $\mathrm{T}-\mathrm{N}$ increased again in the second half period of run after dropping during the first stage. On the contrary, nitrogen was monotonically consumed in Case- 3 in spite of both MB aeration and FAC carriers being absent. Now, let us consider what caused T-N recovery after tentative decrease at the first half stage of Case- 1 and 2. As seen in Fig. 6, $\mathrm{NH}_{4}-\mathrm{N}$ quickly decreased during the beginning in both cases, while increasing tendency of $\mathrm{NO}_{3}-\mathrm{N}$ in Fig. 8 did not show such a quick response. Despite the fact that nitrite nitrogen, $\mathrm{NO}_{2}-\mathrm{N}$, must be intermediately produced to compensate the nitrogen balance, the detected quantity of $\mathrm{NO}_{2}-\mathrm{N}$ during Run- 2 and 3 in Fig. 7 was too small to compensate such a nitrogen balance. Here, notice that the tentative increase of $\mathrm{NO}_{2}-\mathrm{N}$ recorded during Run-1 is not in the scope of discussion, because the biological process was not yet in an equilibrium state during Run-1.

$\mathrm{NO}_{2}$-N's behaviour during the first half stage of Run-2 and 3 was considered to be like the following. Although $\mathrm{NO}_{2}-\mathrm{N}$ was supposed to be tentatively produced by the $\mathrm{MB}$ aeration, it was so unstable that it was immediately denitrified into $\mathrm{N}_{2}$ and disappeared from the sampler before the sampling container was transported to the laboratory. On the other hand, during the latter half stage of Run-2 and 3, nitrite-oxidizing bacteria were well acclimated to directly oxidize most of $\mathrm{NH}_{4}-\mathrm{N}$ into $\mathrm{NO}_{3}-\mathrm{N}$. In this way, all the ammonia nitrogen was immediately converted into $\mathrm{NO}_{3}-\mathrm{N}$ before the laboratory examination and $\mathrm{T}-\mathrm{N}$ in the sampler was eventually preserved well.

Focusing on $\mathrm{NO}_{2}-\mathrm{N}$ during Run-1 in Fig. 7, a non-negligible level of $\mathrm{NO}_{2}-\mathrm{N}$ was detected both in Case-1 and 2, which suggests that nitrite-oxidizing bacteria was not sufficiently acclimated during Run-1 in Case- 1 and 2 as mentioned before. On the other hand, little $\mathrm{NO}_{2}$ $\mathrm{N}$ was detected in Case-3 even during Run-1. It is estimated that $\mathrm{NH}_{4}-\mathrm{N}$ was so slowly oxidized due to the absence of $\mathrm{MB}$ aeration that the rate of the ammonia oxidization from $\mathrm{NH}_{4}-\mathrm{N}$ to $\mathrm{NO}_{2}-\mathrm{N}$ was well balanced to that of the nitrite oxidization from $\mathrm{NO}_{2}-\mathrm{N}$ into $\mathrm{NO}_{3}-$ $\mathrm{N}$. After all, little $\mathrm{NO}_{2}-\mathrm{N}$ could remain in such an equilibrium state.

As seen in Fig. 6, the dissipation rate of $\mathrm{NH}_{4}-\mathrm{N}$ is highest in Case-2, followed in descending order by Case- 1 and 3 during every experimental run. Production rate of $\mathrm{NO}_{3}-\mathrm{N}$ corresponds to this order as seen in Fig. 8. It is a matter of course that Case-3 indicates the lowest nitrification rate, since no MB aeration was conducted. Nitrification in Case- 1 is slower than Case-2, because more oxygen was consumed in Case-1 for decomposing dissolved organic components that were desorbed from FAC, while no FAC was filled in Case-2.

In order to discuss how the MB aeration contributed to nitrification, dissipating rates of $\mathrm{NH}_{4}-\mathrm{N}$ both in Case- 1 and 2 are compared between Run- 2 and Run-3. Fig. 6 well documents that Run-2 shows faster nitrification than Run-3 in both cases, where Run-2 was operated with larger aeration discharge than Run-3. It can be concluded from the result that nitrification was predominantly limited by DO rather than by microorganism condition 


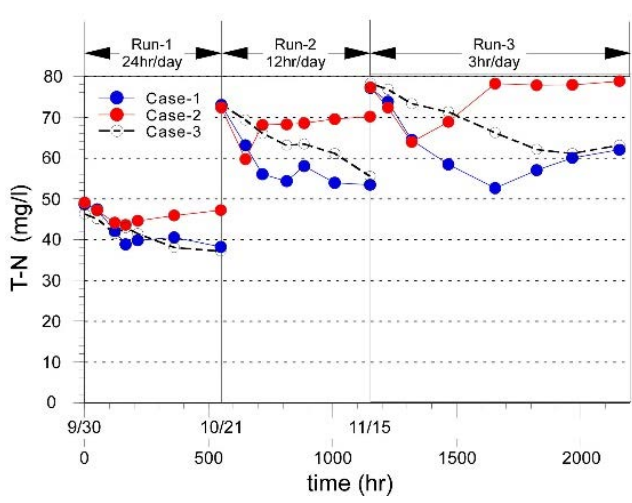

Figure 5: Total nitrogen, T-N.

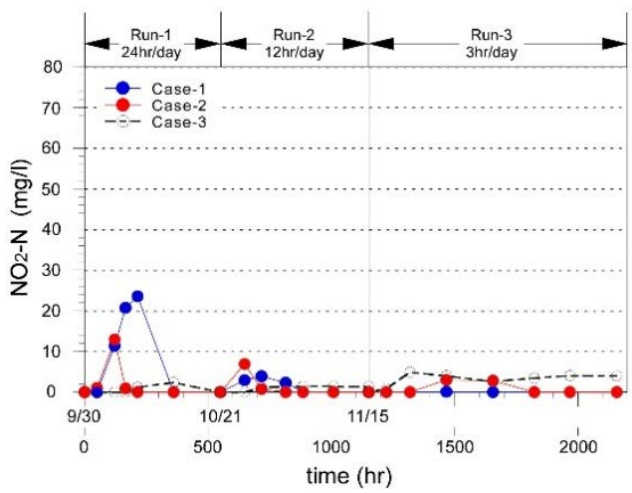

Figure 7: Nitrite nitrogen, $\mathrm{NO}_{2}-\mathrm{N}$.

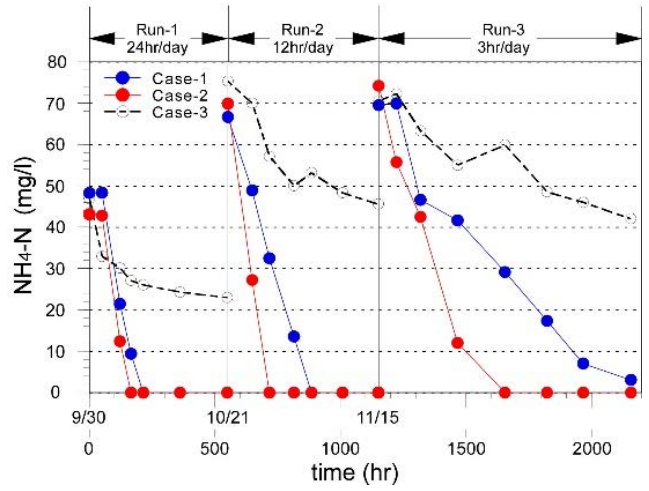

Figure 6: Ammonia nitrogen, $\mathrm{NH}_{4}-\mathrm{N}$.

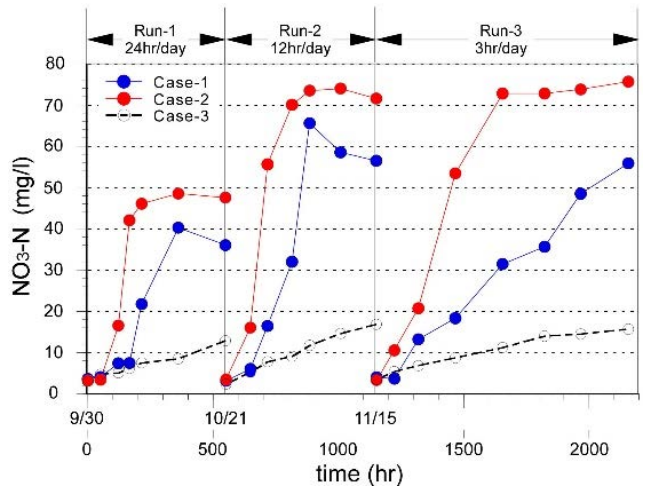

Figure 8: Nitrate nitrogen, $\mathrm{NO}_{3}-\mathrm{N}$.

during Run-2 and 3. On the other hand, the limiting factor during Run-1 was the microorganism condition as discussed before.

Dissipation of DO in every case recorded in Fig. 9 shows a tendency well correlated with those found in $\mathrm{NH}_{4}-\mathrm{N}$ and $\mathrm{NO}_{3}-\mathrm{N}$ from Figs 6 and 8 . Such a close relationship between DO and nitrogen components is observed in Case-3, too, in spite of no MB aeration. Note that, in Case-3, weak nitrification was naturally driven by oxygen exchange between the air-water interface even after consuming DO. In Case-2, where only MB aeration was performed in the absence of FAC, DO was consumed for oxidizing $\mathrm{NH}_{4}-\mathrm{N}$ at the initial stage but it increased in turn after $\mathrm{NH}_{4}-\mathrm{N}$ was completely spent out. In Fig. 9, Case-1 showed a behaviour of DO similar to Case-2 but it was kept at a lower level than that of Case-2, because DO was partially consumed for decomposing organic matters desorbed from FAC. Through comparison between Run-2 and 3 in Case- 1 it is represented that Run-3 had lower DO concentration than Run-2, because during Run-3, the MB aerator was operated with a quarter of Run-2's discharge.

Now, attention is focused on Case- 1 where nitrification and denitrification simultaneously took place with the aid both of the MB aeration and the FAC coated carriers. Since, in the 


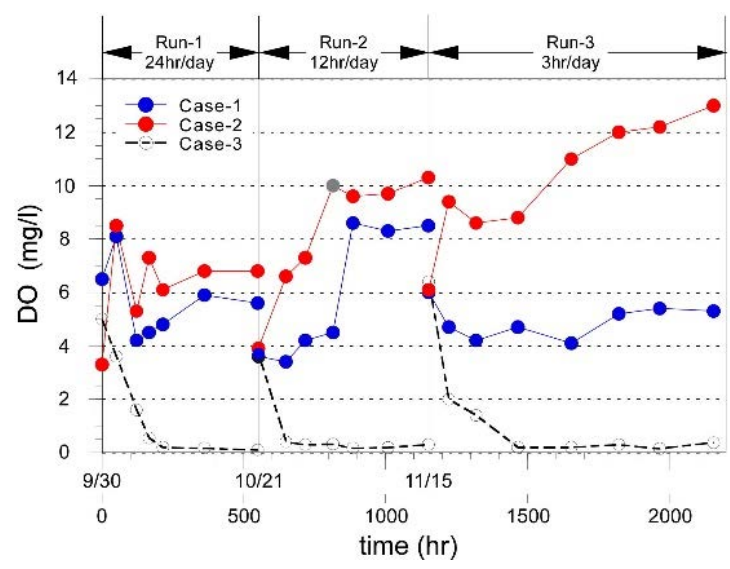

Figure 9: Dissolved oxygen, DO.

first half duration of Run-2 and 3, DO was consumed for oxidizing $\mathrm{NH}_{4}-\mathrm{N}$, DO was in a low concentration level ranging around $4-5 \mathrm{mg} / \mathrm{l}$. Although this was still in an excessively aerobic condition for denitrifying bacteria, denitrification was achieved to some extent as seen in Fig. 5. Denitrification mechanism in such aerobic water is supposed to be as follows. In a thin sublayer on the surface of FAC carrier, microorganism colony or biofilms primarily composed of denitrifying bacteria developed and it was kept anoxic due to DO dissipation for decomposing organic matters desorbed from FAC. Additionally, FAC fed hydrogen and carbon to nourish the denitrifiers. In this way, denitrification took place locally in the anoxic sublayer on the microorganism biofilm even though the ambient water was kept aerobic. However, after spending out $\mathrm{NH}_{4}-\mathrm{N}$ by nitrification, $\mathrm{DO}$ was eventually so oversupplied that its concentration began to increase during the latter half period of Run-2 and 3 as seen in Fig. 9. Denitrification in the microorganism biofilm then declined with the increased DO and T$\mathrm{N}$ asymptotically approached a constant concentration without becoming denitrified.

Since the experiment was carried out in a closed system with no leachate loading, denitrification in Case- 1 was terminated in the middle stage of Run-2 and 3 after spending out $\mathrm{NH}_{4}-\mathrm{N}$ as shown in Fig. 5. Therefore, the total denitrified amount of $\mathrm{T}-\mathrm{N}$ in the end of run in Case-1 was in the same level as that in Case-3. Here, the system was naturally and slowly denitrified even in Case-3, where the MB aeration was absent. However, attention should be paid on the decreasing rate of T-N recorded in the first half period of Run-2 and 3 in Fig. 5, which clearly shows a higher denitrification rate in Case-1 than in Case-3. If fresh leachate was continuously loaded to the test tank, more T-N is expected to be removed in Case- 1 by the combined effects of MB aeration and FAC carriers.

\subsection{Total organic carbon, TOC, and phosphoric acid, $\mathrm{PO}_{4}-\mathrm{P}$}

The denitrifiers are generally heterotrophic bacteria that are nourished by organic substance and phosphoric acid. Figs 10 and 11 show the time-series of total organic carbon, TOC, and phosphoric acid, $\mathrm{PO}_{4}-\mathrm{P}$, respectively. The dominant component of TOC is hardly decomposable organic substances that were originally contained in the leachate. Therefore, little difference is recognized in TOC among the three cases. The hardly decomposable organic substances scarcely decompose nor are consumed for nourishing the denitrifying 


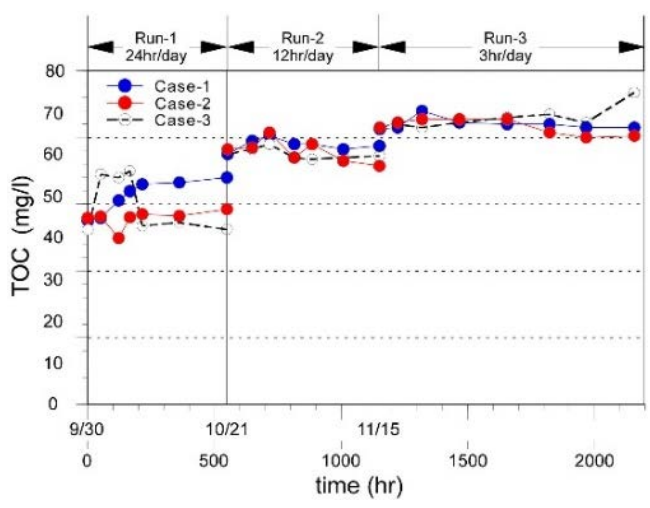

Figure 10: Total organic carbon, TOC.

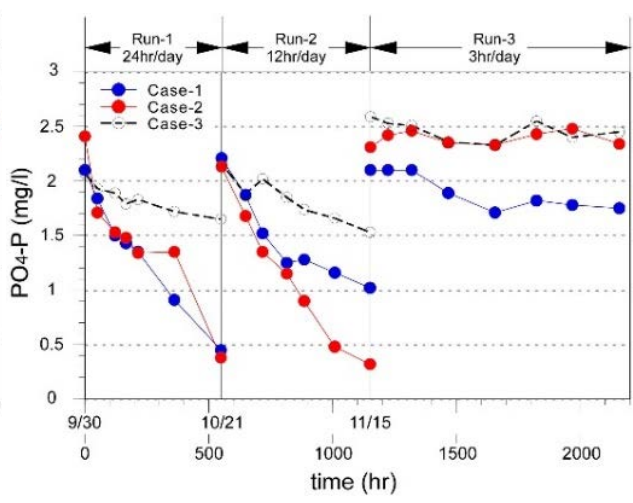

Figure 11: Phosphoric acid, $\mathrm{PO}_{4}-\mathrm{P}$.

bacteria in the reactor. For this reason, it is difficult to discuss based on Fig. 10 how the organic substance released from FAC was used in the treatment process. On the other hand, it is easily recognized that $\mathrm{PO}_{4}-\mathrm{P}$ was consumed by nitrification in Case- 2 in addition to by denitrification in Cases 1 and 3. This shows that the phosphoric acid played an important role as a nutrient source not only for nitrifiers but also for and denitrifiers. While $\mathrm{PO}_{4}-\mathrm{P}$ showed a similar level of dissipation rate between Case- 1 and 2 during Run-1 and 2, Case 3 consumed much less $\mathrm{PO}_{4}-\mathrm{P}$ than the other two cases. It suggests that $\mathrm{PO}_{4}-\mathrm{P}$ dissipation depends more on nitrification than on denitrification; in other words, the nitrifier needs more $\mathrm{PO}_{4}-\mathrm{P}$ than the denitrifier. This is confirmed again in Fig. 10 by comparing Case- 1 and 2 during Run- 2 . Namely, the figure indicates that more $\mathrm{PO}_{4}-\mathrm{P}$ was spent in Case- 2 than in Case- 1 , since denitrification scarcely occurred in Case-2, whereas nitrification and denitrification were simultaneously in progress in Case- 1 . Little $\mathrm{PO}_{4}-\mathrm{P}$ was consumed during Run-3 in all three cases. This may come from termination of acclimatization at the end of Run-2 or from the reduced microbial activities in the low water temperature during Run-3.

\section{EFFECTS OF MICRO-BUBBLE AERATION AND FATTY ACID COMPOUNDS ON BALANCES OF DISSOLVED OXYGEN AND NITROGEN REMOVAL}

\subsection{Balance of dissolved oxygen, DO}

Let us consider how DO was influenced by the MB aeration, nitrification and denitrification. DO production and dissipation processes in the present treatment system is conceptually illustrated in Fig. 12.

Time histories of cumulative consumption of DO are plotted in Figs 13-15, where the number in parentheses indicates each component of DO gain or loss mentioned in Fig. 12.

Thin solid curves are deviation of DO concentration from the initial value of each experimental run, which is termed to be "apparent DO consumption", hereafter. Thick solid lines indicate cumulative consumption of DO that was estimated from variation of $\mathrm{NH}_{4}-\mathrm{N}$ and $\mathrm{NO}_{2}-\mathrm{N}$ concentration by using the chemical equilibrium equations for ammonia and nitrite oxidization. In Fig. 13, the cumulative curves of DO consumption from Case-2 are also plotted in thick broken lines with Case-1 to examine how the denitrification affects DO balance. In the same manner, the cumulative curves of Case- 3 are also plotted in thick broken lines in Fig. 14 (Case-2) to examine the effect of MB aeration on DO balance. 

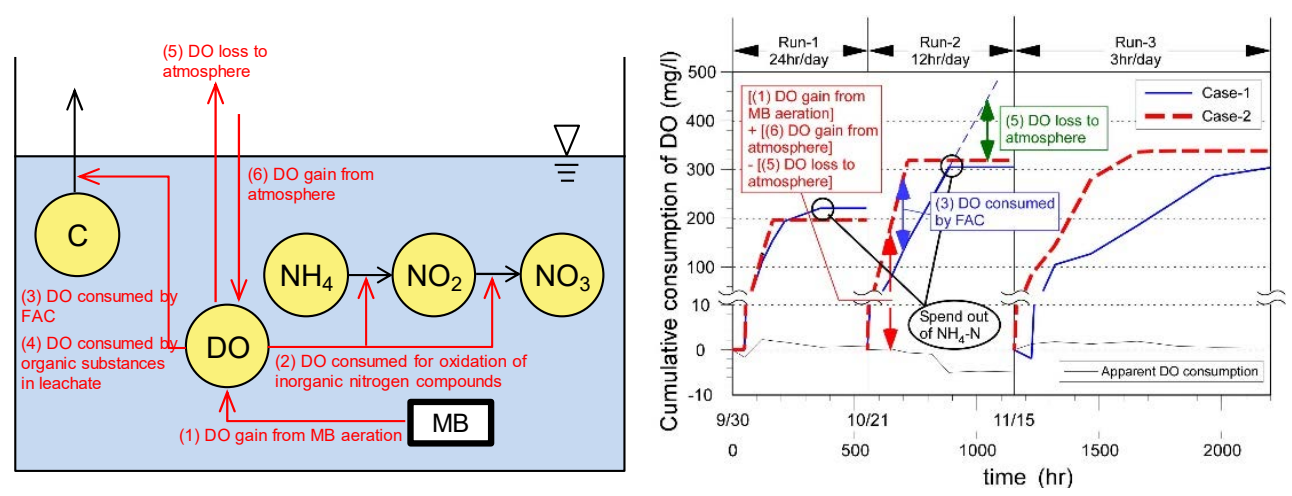

Figure 12: Concept of DO balance in Figure 13: Cumulative DO consumption the present treatment system.

and deviation of DO concentration from the initial value (Case-1).
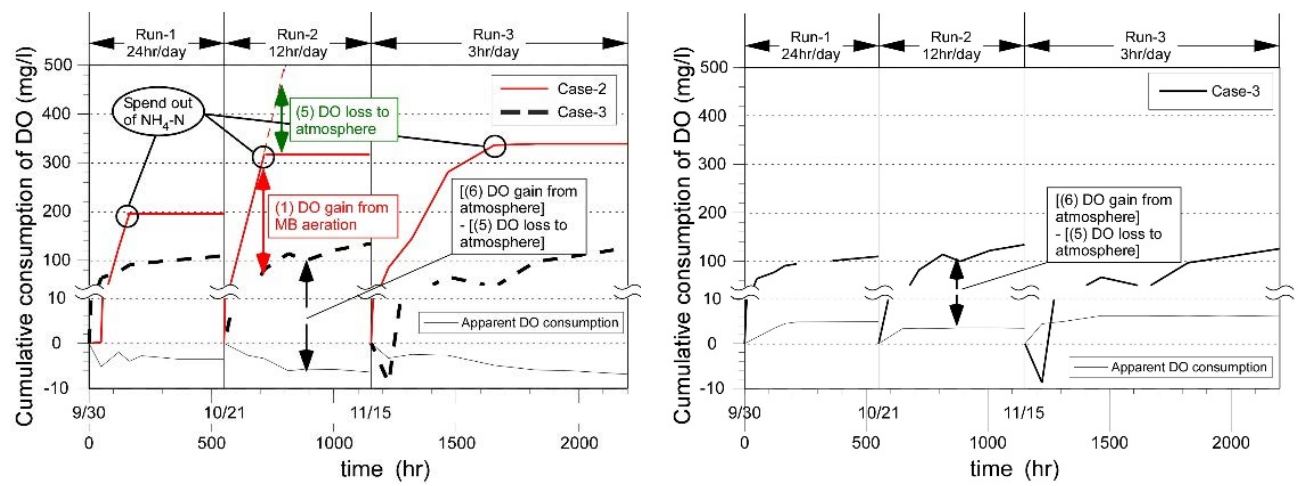

Figure 14: Cumulative DO consumption Figure 15: Cumulative DO consumption and deviation of DO concentration from the initial value (Case-2). and deviation of DO concentration from the initial value (Case-3).

Fig. 15 is the result from Case-3. The consumed quantity of DO (thick solid lines) at the end of each run is about twenty times larger than the apparent DO consumption (thin solid lines). This shows that a certain quantity of DO was naturally fed by the oxygen exchange across the water surface even without the MB aeration. This is equivalent to [(6) DO gain from atmosphere to water body]-[(5) DO loss from water body to atmosphere] as indicated by the vertical arrow in Fig. 15.

It is considered that DO was mostly spent by nitrification in Case- 2 since the carriers were not coated with FAC. As shown in Fig. 14, the consumed quantity of DO (thick solid lines) was about three times larger than that of Case-3 (thick broken lines). The difference between the two cases shown in the red vertical arrow then corresponds to the quantity of (1) DO fed 
from the MB aerator. Additionally, events during Run-2 shown in Fig. 14 indicates that DO was no longer consumed for nitrification after the elapsed time of $717 \mathrm{hr}$ when $\mathrm{NH}_{4}-\mathrm{N}$ was spent out. The MB aeration still continued even after $717 \mathrm{hr}$ and DO would be further consumed as extrapolated in the red thin broken line if $\mathrm{NH}_{4}-\mathrm{N}$ was still left in the tank. In reality, there was no more $\mathrm{NH}_{4}-\mathrm{N}$ left and all of the $\mathrm{DO}$ was directly ventilated to atmosphere without spending for nitrification. As a result, loss of DO from the water body to atmosphere, i.e. [(5) DO loss from water body to atmosphere], can be estimated as the green vertical arrow in the figure. The same tendency of DO after spending out of $\mathrm{NH}_{4}-\mathrm{N}$ is observed in the cumulative curves during Run-1 and 3, too, which is marked in open circles.

Deviation of the cumulative curve of Case-2 (thick broken line) from that of Case-1 (thick solid line) in Fig. 13 corresponds to the consumed quantity of DO to decompose organic matters desorbed from FAC, which is termed as "(3) DO consumed by FAC". This is marked by the blue vertical arrow in the figure.

\subsection{Balance of nitrogen components}

Now consider Run-1 to be an acclimatization operation because the biochemical system was not sufficiently in an equilibrium state, yet. Therefore, paying attention especially on Run-2 and 3, discussion will be made on the influence of the MB aeration and FAC carriers on the nitrogen removal performance.

Time histories of T-N during Run-2 and 3 in Fig. 5 are rearranged and overlaid in Fig. 16. It is reconfirmed that Case-1 has higher denitrification performance than Case-2. Therefore, difference of T-N between the two cases marked by the green vertical arrow corresponds to the quantity of nitrogen removed by FAC. In Fig. 16, little difference was found in denitrification performance between Run-2 and 3 especially during the latter half period both in Case-1 and 2. Here, notice that the MB aerator during Run-3 was operated with a quarter of Run-2's discharge. The reason of such a small difference in denitrification rate between Run- 2 and 3 is considered that, during both of the runs, denitrification was terminated in the middle stage due to the oversupplied oxygen after spending out $\mathrm{NH}_{4}-\mathrm{N}$.

The dataset of $\mathrm{NH}_{4}-\mathrm{N}$ from Fig. 6 is rearranged in Fig. 17 in the same manner as in Fig. 16. Both during Run-2 and 3, Case-2 shows a higher ammonia oxidization rate than Case-1, which proved that the FAC reduced ammonia oxidization. The green vertical arrow in the figure denotes the difference between the two cases. Additionally, the figure shows that Run3 has a slower ammonia oxidation rate than Run-2, since Run- 2 was operated with higher aeration discharge. The purple vertical arrow quantifies the difference in T-N between the two runs.

In order to summarize the effects of $\mathrm{MB}$ aeration and FAC on the nitrogen removal performance, nitrification and denitrification rates are calculated from the dataset only during the periods nitrification and denitrification were simultaneously in progress. The result is shown in Fig. 18. Here, considering Case- 3 to be a reference case, the nitrification and denitrification rates in Case- 1 and 2 were evaluated by taking differences between the rates in two cases and that in Case-3.

In Case-1, both the nitrification and denitrification rates took positive values during Run2 and 3. On the other hand, in Case-2, it was observed that nitrification was certainly achieved, and denitrification performance was slightly lower than Case-3. It was also confirmed in Case-1 that denitrification during Run-3 less than Run-2 in spite of smaller aeration discharge during Run-3. This may come from by the smaller production of $\mathrm{NO}_{3}-\mathrm{N}$ during Run-3. 


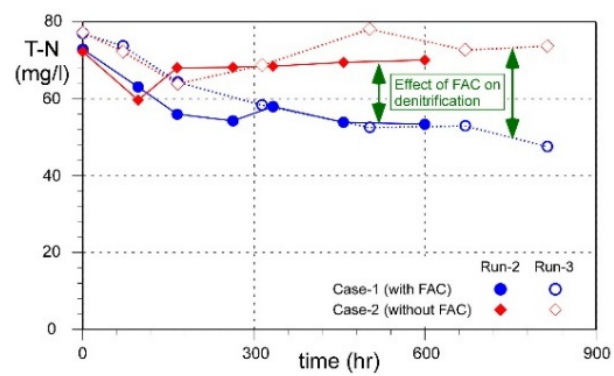

Figure 16: Time dependent behaviour of T-N during Run-2 and 3 (rearrangement of Fig. 5).

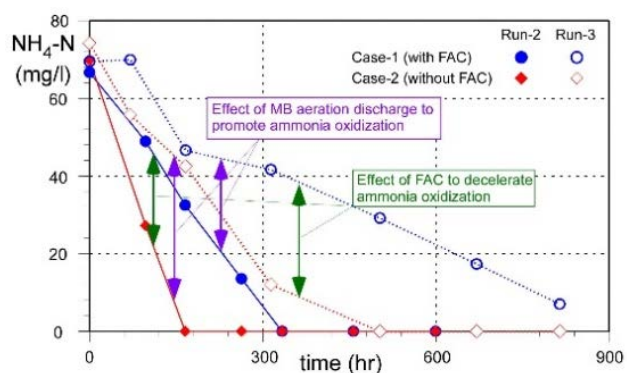

Figure 17: Time dependent behaviour of $\mathrm{NH}_{4}-\mathrm{N}$ during Run-2 and 3 (rearrangement of Fig. 6).

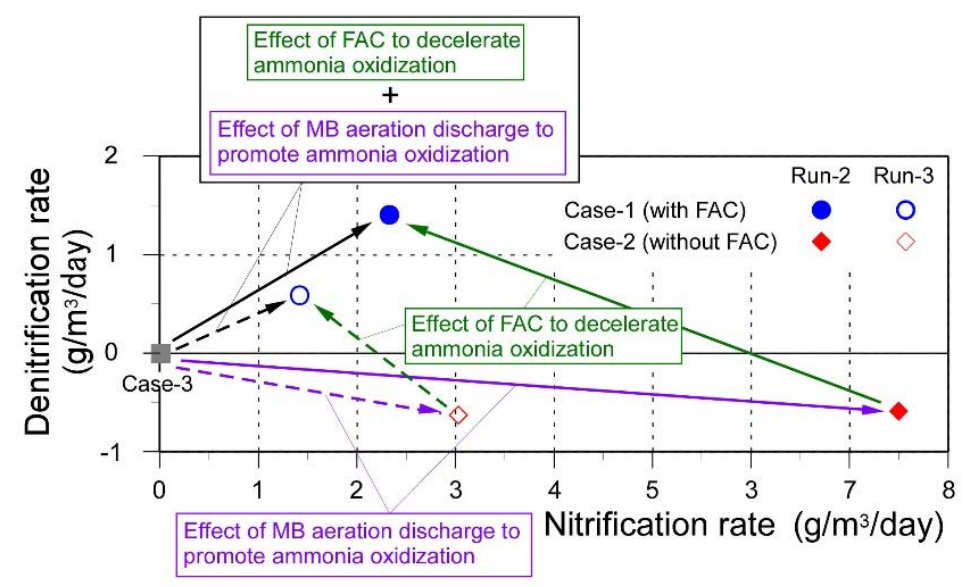

Figure 18: Nitrification rate versus denitrification rate during Run-2 and 3 in Case-1 and Case-2.

\section{DISCUSSION AND CONCLUDING REMARKS}

In order to develop a new technology for an economically feasible treatment system for municipal landfill leachate, a laboratory experiment was carried out, where both the nitrification and denitrification simultaneously took place in a single reactor. Oxidizing the leachate by a micro-bubble (MB) aerator, ammonia nitrogen was converted into nitrite and nitrate nitrogen. Then, they were biochemically denitrified in an anoxic sublayer formed on the surface of microorganism carriers with coating of fatty acid compounds, FAC. FAC promoted denitrification by nourishing heterotrophic bacteria as hydrogen donor and carbon source. It was proved that both the nitrification and denitrification were simultaneously in progress in a single reaction tank with the aid of MB aeration and FAC coated carriers. In order to experimentally investigate the nitrogen removal performance, individual contribution of the $\mathrm{MB}$ aeration and $\mathrm{FAC}$ on the nitrification and denitrification was evaluated based on the experimental data. 
The problem in the experimental system is that the experiment was carried out in a closed test tank with no leachate loading. Ammonia nitrogen was consumed out in the middle stage of experimental run and denitrification was not completely terminated in such a closed experimental system. In order to more precisely quantify treatment performance, the experiment should be conducted in a system with continuous loading of leachate. By doing so, the most optimum operational conditions for the treatment system such as leachate loading rate, $\mathrm{MB}$ aeration discharge, quantity of FAC carriers and dimensions of the reactor could be found from the experiment. A further investigation is also required by developing a water quality model to analytically reproduce the biochemical process in the present system. By applying the model to a prototype-scale facility, an optimum design of the highest performance of leachate treatment system with minimum cost and energy is expected to be achieved.

\section{ACKNOWLEDGEMENT}

The present study was financially supported by the Grant-in-Aid for Scientific Research (C) (Project No. 17K06588, Leader: Kohji Michioku).

\section{REFERENCES}

[1] Borzacconi, L., Ottonello, G., Castell, E., Pelaez, H., Gazzola, A. \& Vi, M., Denitrification in a carbon and nitrogen removal system for leachate treatment: performance of a Upflow Sludge Blanket (USB) Reactor. Water Science and Technology, 40(8), pp. 145-152, 1999.

[2] Diamadopoulos, E., Samaras, P., Dabou, X. \& Sakellaropoulos, G.P., Combined treatment of land-fill leachate and domestic sewage in a sequencing batch re-actor. Water Science and Technology, 36(2-3), pp. 61-68, 1997.

[3] Zhu, R., Wang, S., Li, J., Wang, K., Miao, L., Ma, B. \& Peng, Y., Biological nitrogen removal from landfill leachate using anaerobic-aerobic process: Denitrification via organics in raw leachate and intracellular storage polymers of microorganisms. Bioresource Technology, 128, pp. 401-408, 2012.

[4] Cema, G., Wiszniowski, J., Żabczyński, S., Zabłocka-Godlewska, E., Raszka, A. \& Surmacz-Górska, J., Biological nitrogen removal from landfill leachate by deammonification assisted by heterotrophic denitrification in a rotating biological contactor (RBC). Water Science and Technology, 55(8-9), pp. 35-42, 2007.

[5] Hasar, H., Ipek, U. \& Kinaci, C., Joint treatment of landfill leachate with municipal wastewater by submerged membrane bioreactor. Water Science and Technology, 60(12), pp. 3121-3127, 2009.

[6] Bashir, M.J.K., Aziz, H.A., Yusoff, M.S., Huqe, A.A.M. \& Mohajeri, S., Effects of ion exchange resins in different mobile ion forms on semi-aerobic landfill leachate treatment. Water Science and Technology, 61(3), pp. 641-649, 2010.

[7] Polprasert, C. \& Sawaittayothin, V., Nitrogen mass balance and microbial analysis of constructed wetlands treating municipal landfill leachate. Water Science and Technology, 54(11-12), pp. 147-154, 2006.

[8] Jokela, J.P.Y., Kettunen, R.H., Sourmunen, K.M. \& Rintala, J.A., Biological nitrogen removal from municipal landfill leachate: low-cost nitrification in biofilters and laboratory scale in-situ denitrification. Water Research, 36(2002), pp. 4079-4087, 2002.

[9] Bratanow, T. \& De Grande, G., Numerical analysis of normal stress in non-Newtonian boundary layer flow. Engineering Analysis, 6(2), pp. 20-25, 1985. 
[10] Michioku, K., Micro-bubble aeration of polluted leachate from a landfill. Proceedings of 33rd IAHR Congress, CD-ROM, 2009.

[11] Michioku, K., Nakamichi, T., Yagi, M. \& Wada, N., A water quality model for aeration of leachate from garbage dumped landfill. Proceedings of 6th Int. Symp. Environmental Hydraulics, 2, pp. 1053-1058, 2010.

[12] Inoue, K., Tanaka, K., Michioku, K., Tanaka, H., Yagi, M. \& Nakamichi, T., A field experiment and water quality modeling on nitrification of waste landfill leachate by using micro-bubble aeration. Proceedings of 35th IAHR World Congress, CD-ROM, 2013.

[13] Michioku, K., 4.2 Purification of water quality. Micro- and Nanobubbles: Fundamentals and Application, ed. H. Tsuge, Pan Stanford Publishing Pte. Ltd.: Singapore, 2014.

[14] Michioku, K., Tanaka K., Yagi M., Nakamichi, T. \& Wada, N., An experimental study on denitrification of leachate continuously loaded from a municipal waste landfill. Groundwater Modeling and Management under Uncertainty, eds Hadi \& Copty, Taylor \& Francis Group, 2012. 